\title{
VARIA
}

\section{EL SERMÓN 127 DE SAN PEDRO CRISÓLOGO Y EL JARDÍN DE LAS DELICIAS DEL BOSCO}

En 1963 publiqué un artículo sobre el «Grupo de la cueva» (fig. 1) en el panel central del Jardín de las Delicias del Bosco. En él resumía la tesis de Fraenger que interpretaba al hombre vestido como el «nuevo Adán», símbolo de la secta de los Adamitas, que, según él, estaba representada en el tríptico; también aludí a la propuesta de Bax quien había interpretado esa figura como Lucifer tratando de seducir a Eva ${ }^{1}$. Yo basé mi interpretación entonces en el análisis individual de cada uno de los elementos e individuos que componían el grupo de la «cueva» y que no habían sido aludidos por los autores citados. Entre esos elementos estaba el tubo de cristal decorado por once circulitos que cruzaba a la mujer del primer plano, y que teniendo en cuenta la simbología de la época, podía significar la fragilidad humana —el vidrio- y el pecado los once circulitos, ya que este número, por traspasar el diez — número de los Mandamientos - tenía ese simbolismo. Respecto a la figura femenina había un elemento clarísimo que la identificaba con Eva, la manzana que llevaba en la mano. Respecto al sello o tapón que había sobre sus labios y que le otorgaba carácter de Sibila o guardadora de un secreto, lo comparé con el candado del hombre que, con los labios sellados por él, aparecía en el grabado de Peter Brueghel, las Brujas de Malleghen, en un lugar recóndito - como Eva - debajo de la mesa y mostrando en la mano un órgano masculino que, como protagonista del grabado, representaba la castración ${ }^{2}$.

La débil consistencia de las propuestas de Fraenger y Bax y basándome sólo en lo que veía, identifiqué a la figura del hombre vestido con indumentaria de «pelo» como el Bautista, ya que la actitud de estar «señalando» con el dedo índice era una constante en la iconografía del santo. La única diferencia estaba en que lo que tradicionalmente señalaba San Juan era el Cordero «que quita el pecado del mundo» y aquí señalaba a Eva, que representaba todo lo contrario, pues, por su desobediencia en el paraíso, «trajo el pecado al comerse la manzana». Existían no obstante otras representaciones artísticas donde el Bautista «señalaba» al manzano, o aparecía acompañado de la serpiente. La figura que había en la cueva detrás de él era sin duda Adán.

\footnotetext{
1 «El Grupo de la cueva en el panel central del Jardín de las Delicias del Bosco», Archivo Español de Arte 1963, p. 253. A propósito del gesto para indicar silencio, véase, K. Langedijk: «Silentium» en Nederlans Kunsthistorisch Lahrbock, 1968, p. 3, como virtud a partir del emblema de Alciato, n.. XI. A. Chastel «Signun harpocratium» en Studi in honore Giulio Carlo Argan, Roma, 1984, p. 147, donde se dice que fue un gesto muy común durante el Humanismo, y que Ovidio (Met, IX, 692), lo utilizaba con un sentido de taciturnidad y melancolía.

2 W. Fraenger, The Millenium of Hieronymus Bosch. Chicago, 1951 (1. ed. en Alemania, 1947). D. Bax, Onteijfering van Jeroen Bosch, La Haya, 1949.
} 
Hace algunos años Patric Reuterswärd publicó un estudio sobre este grupo de la «cueva», observando que Eva estaba cubierta de vello por los brazos, lo mismo que el hombre que había detrás de ella cubría el cuerpo, llegando a la conclusión de que se trataba de una pareja de «salvajes», que en el contexto de la tabla, representaban una alternativa, una opción moral a la corrupción del siglo XV. Reuterswärd reconoce que era frecuente representar a Adán y a Eva como «salvajes» en aquella época, pero no menciona a la tercera figura que aparece en la cueva, ni a la otra pareja de «salvajes» que hay en el grupo que se halla a la izquierda de las figuras de la «cueva» y a las que luego nos referiremos. Tampoco alude al aspecto negativo o meramente decorativo que tuvieron estos seres exóticos desde el siglo XIII al XVI, ni a que Adán y Eva también aparecían vestidos con pieles de animales en numerosas ocasiones. Recientemente Yarza Luaces prescindiendo de la identificación de la figura del fondo de la cueva y no apercibiéndose de la pareja de «salvajes» que hay junto a ella, interpreta a la pareja del primer término de ésta como Adán y Eva, que van cubiertos de pieles según San Agustín porque Dios se las entregó como símbolo de la mortalidad de esta vida después de la caída ${ }^{3}$.

Respecto al aspecto decorativo del salvaje su presencia es abrumadora en todas las manifestaciones artísticas: miniaturas, sillerías de coro, fachadas de los edificios, grabados, jambas de puertas etc. y hablan en favor de su prodigalidad, los dibujos y grabados que circularon con su imagen, para fuente de los artistas, como por ejemplo en el siglo XV la lámina de Israhel van Meckenem (fig. 3), que se conserva en el Gabinete de Estampas de Viena ${ }^{4}$. Queremos cerrar este aspecto diciendo que en el inventario de la reina Isabel la Católica aparecen tres cuadros del Bosco, un San Antón, unas diablerías y una mujer cubierta de pelo en un prado ${ }^{5}$.

Para alcanzar el significado de estas figuras de «salvajes» hay que estudiarlas dentro del contexto en que se representan, pues con carácter negativo aparece el «salvaje», por ejemplo, en una miniatura francesa del siglo XIV (fig. 4), raptando a una doncella y perseguido por un caballero, tema que se repite en una pintura de la misma época de la Alhambra de Granada ${ }^{6}$.

Como hemos advertido anteriormente, a la izquierda de la «cueva» aparece una pareja de «salvajes» (fig. 2), acompañada por una negra. La mujer recoge el cabello en la parte superior de la cabeza con una humilde violeta mientras que del extremo inferior pende una manzana, como la de Eva; el salvaje que, de frente, conversa con ella, cubriendo ambos el cuerpo con un vello muy sutil apenas resaltado, como el de la mujer de la cueva y que contrasta con el tono intenso y oscuro de la piel que cubre el cuerpo del hombre de la cueva.

Creo importante insistir en la idea que de esos seres exóticos, «salvajes» y «negros», tuvo el hombre medieval. Para ello es importante analizar el concepto de «alteridad», que en aquella época representó lo que era distinto. El hombre medieval sintió inquietud por las gentes y lugares extraños que imaginaba y veía reproducidos en los libros de Marco Polo, Mandeville y la Crónica General, de Schedel, en la que se cita a los «salvajes» como seres nudi et pilosi y a los «negros» como ethiopian (fols. XII-XIV), (fig. 4) llegándose a considerar a estos seres exóticos «san valeur», porque los pueblos sin historia eran los pueblos de la.

3 «A new clou to Boschs Garden of Delights» Art Bulletin 1982, p. 636. Ocho años después P. Vandenbroeck, en un erudito trabajo considera al tríptico como un retorno a la sexualidad natural, evocando, también, a la representación de los «salvajes» como una edad de Oro. «Jeronimus Boschs zogennamde Tuin der Lusten II De Graal of het Valse Liefdesparadijs» Koninklijk. Museum voor Schone Kunsten Antwerpen Jaarbock, 1990. J. Yarza Luaces: El Jardín de las Delicias. Madrid, 1999, p. 66.

4 Barts, Ilustrated... vol. 23, con ejemplos también de otros maestros.

5 F.J. Sánchez Cantón, Libros, tapices y cuadros que coleccionó Isabel la Católica. Madrid, 1950.

6 Randall, L.M.C. Images in the margins of gothic manuscripts, Berkeley. Los Angeles, (fig. 688) 1996. Bermúdez Pareja: Pintura sobre piel en la Alhambra de Granada, Vich, 1974, lam. 6. 
«alteridad» por excelencia. La presencia de individuos de aspecto diferente despertaba no sólo curiosidad — de ahí su abundancia en el campo artístico - sino también sentimientos y reacciones de los valores que podían simbolizar, muy principalmente los de maldad, pecado y muerte, con una evocación conjunta de lo diabólico y la lujuria. También los Padres de la Iglesia y en especial San Gregorio habían identificado a los negros con los predicadores de Satán ${ }^{7}$.

Creo por todo ello que la presencia de negros y salvajes no contradice la intencionalidad del tríptico predicando contra la lujuria, sino que la apoya. De otro lado la presencia del Bautista entre «salvajes» se explica porque por su forma de vivir y vestir cubierto con piel de camello, se le consideró como un «salvaje», lo mismo que a otros santos como San Onofre.

Retomando la antigua identificación mía del hombre de la cueva como el Bautista, en aquella ocasión me faltaba un texto que respaldara su relación directa con Eva, con los deleites y con el fin del linaje humano hacia el infierno. Casualmente lo encontré en el Acto I del libro de Fernando de Rojas, La Celestina, en el que Sempronio dice lo siguiente: « ¿No has rezado en la festividad de San Juan do dice: Esta es la mujer, malicia que Adán echó de los deleites del paraíso; ésta el linaje humano metió en el Infierno?».

No era fácil localizar el texto que sirvió de fuente a Fernando de Rojas para este párrafo. Pude conseguirlo después de revisar diversas ediciones críticas de La Celestina que trataban de las fuentes inspiradoras de sus pasajes. En una de ellas, la de Peter Russell, este autor daba como fuente del citado párrafo, el Sermón 127 de San Pedro Crisólogo ${ }^{8}$. ¿Quién era San Pedro Crisólogo y qué difusión tuvieron sus Sermones para que pudieran haber sido conocidos y utilizados por el Bosco o el comitente del tríptico? San Pedro Crisólogo fue obispo de Rávena, muy conocido y sus obras muy citadas desde el siglo XII al XVI por importantes figuras como Anselmo de Laón, San Buenaventura, Santo Tomás, Jacobo de Voragine, Gerardo de Lieja, etc. De sus ciento setenta y seis Sermones u Homilías, que coleccionó Félix, Obispo de Rávena, fue precisamente el 127 el más divulgado. Todos los Sermones comentan los textos sagrados no sólo literalmente sino también con un sentido místico y alegórico. De los muchísimos manuscritos que circularon de sus Sermones por Europa hubo algunos en los Países Bajos, en Brujas y Bruselas ${ }^{9}$. Sabemos que Felipe II, en 1545, cuando aún era príncipe, compró dos ejemplares, uno bajo el título Sermones Petri Chrysologi y otro Homiliae Chrysologi ${ }^{10}$.

El Sermon 127 de Crisólogo lleva por título «sobre la decapitación de San Juan Bautista» ${ }^{11}$. En él se describe al Bautista como modelo de virtudes y muy particularmente de la virginidad, contraponiéndole a Herodes, compendio de vicios singularmente de la lujuria. Reflexiona el texto sobre la paradoja de que el vicio sea quien acuse y encarcele a la virtud representada por el Bautista, quien no quería la perdición de Herodes, sino su bien, advirtiéndole de sus pecados. Respecto a Eva, reproducimos el texto referido a ella:

7 E. Benito Ruano, De la Alteridad en la Historia. Discurso leído en la Real Academia de la Historia. Madrid, 1988. H. Calas, «The Ethiopians in Bosch Garden». Coloquio, 1980, n. ${ }^{\circ} 46$, pp. 12-23. En los relatos de los viajeros medievales las descripciones irreales de imágenes geográficas y zoomórficas, pudieron servir también para la fantasía desplegada por el Bosco en los fondos paisajísticos del tríptico y de sus animales. Curiosamente son once los negros que aparecen en el Jardín de las Delicias y hemos visto que este número simboliza el pecado. A. Schedel: Registrum operis libri Cronicarum. Nuremberg, 1493. También se conoció por Gronica General y Creatis Mundi.

8 F. de Rojas, La Celestina. Madrid, ed. Castalia, 1991, Estudio crítico por Peter Russell.

9 Enciclopedia LABAC: Los Sermones de San Pedro Crisólogo. Estudio crítico por Alejandro Olivar Abadi de Monserrat, 1962. Colección «Scripta et Documenta».

10 Libranzas a Cristóbal de Estrella, quien los compró (Librería de Felipe II. Madrid. Revista de Archivos, 1927).

11 Traditio Catholica. Saeculum V, Annus 450. Sancti Petri Chrysologo Archipiescopi Ravennalis. Opera Omnia. Patrologiae Latinae Tomns 52. Turnholti (Belgium) pp. 550-552. 


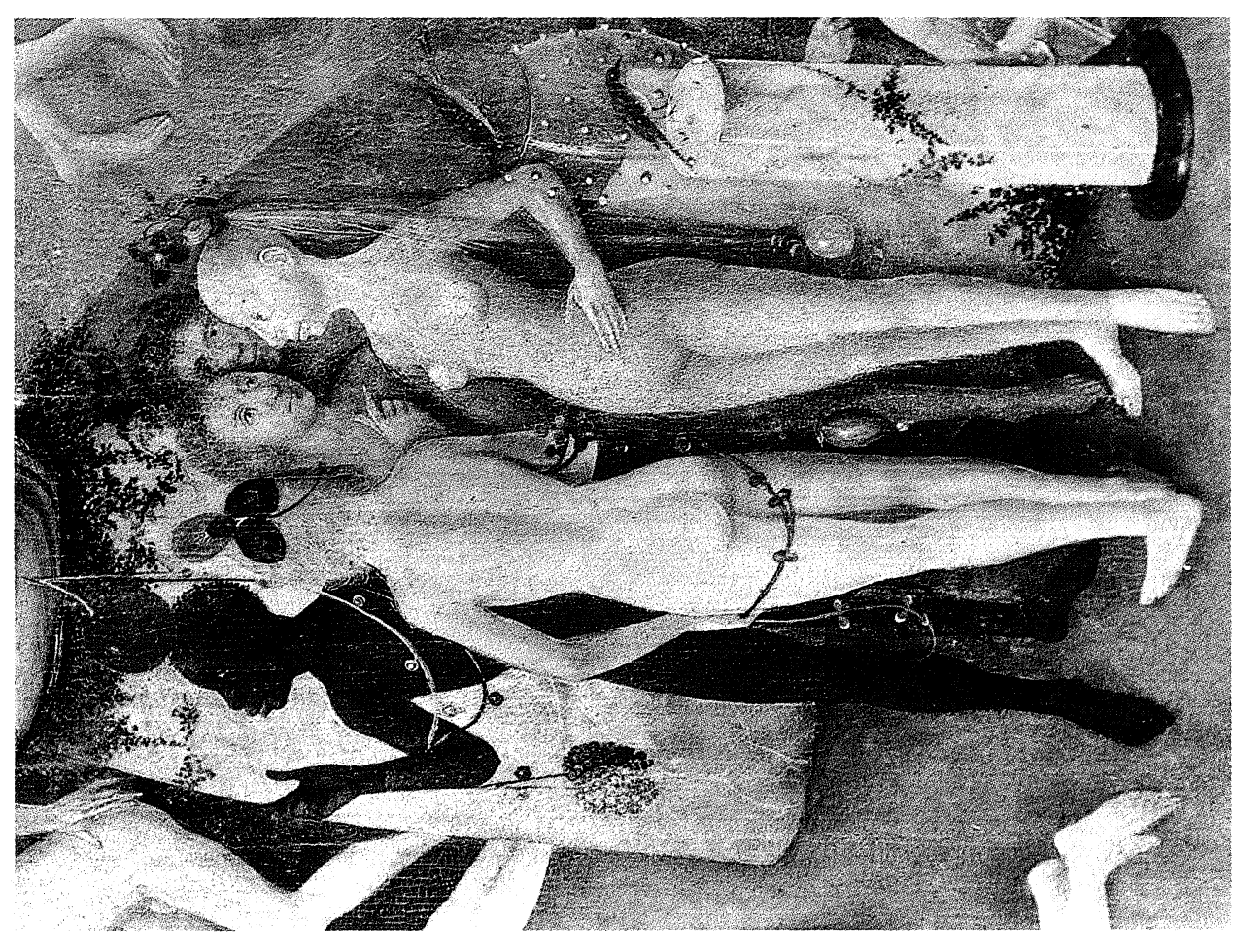

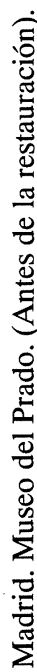

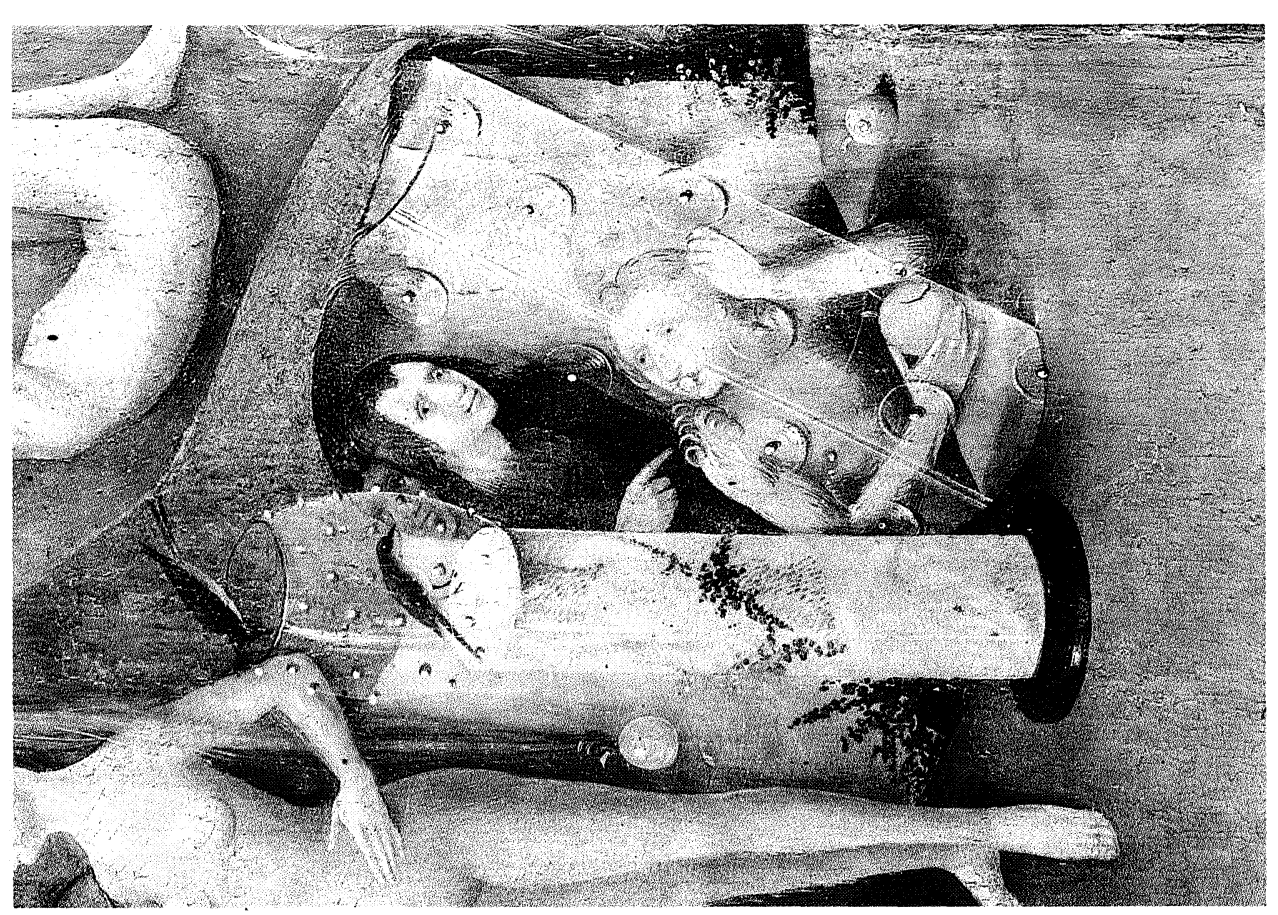




«Haec est mulieris antiqua malitia, quae Adam ejecit de paradisi deliciis (Gen III): haec coelestes homines fecit esse terrenos, haec humanum genus misit in infernum, haec vitam abstulit mundo propter unius arboris pomum. Hoc malum quod homines ducit ad mortem, hoc malum fugit Elias Profeta (III Reg XIX); et cuyus lingua clavis facta est coeli, tamquam reus fugit a faci mulieris; haec invenit verum laborem et pressuram, quae nunc occidit Joannem Baptistam, dejicit pueritiam, perdit juventutem, illicit et inquietat emortuam sectutem».

«Ésta es la antigua malicia de la mujer que expulsó a Adán de las Delicias del Paraíso (Gen 3); ésta es la que hizo que los hombres celestiales se volvieran terrenales, envió al Infierno al género humano, privó de vida al mundo por el fruto de un sólo árbol. Este mal que conduce a los hombres a la muerte, es el que evita el profeta Elías (III, Reyes, XIX); y aquél cuya lengua se ha convertido en la llave del cielo huye como reo de la faz de la mujer; ésta despliega el verdadero esfuerzo y presión que ahora mata a Juan el Bautista, malogra a los niños, pervierte a la juventud, seduce y atormenta a los ancianos moribundos» ${ }^{12}$.

Relacionado con Eva se escribe en el siglo XV la Danza de la Manzana, que recuerda al hombre cómo la Muerte nace al cometer Adán y Eva el Pecado Original.

No se sabe para quién fue pintado el tríptico, suponiendo algunos autores que pudo ser un encargo de Enrique III de Nassau con motivo de su primer matrimonio en 1503 o de su segundo en 1511. No obstante, respecto a la cronología pensamos que la presencia de los «salvajes» de moda en el siglo XV y la evidente utilización por parte del Bosco de algunos grabados de la Crónica de Schedel, de 1493, hace pensar que el tríptico pudo pintarse entre esta fecha y el fin de la centuria. Felipe II compró el tríptico en la almoneda del prior don Fernando Álvarez de Toledo, hijo ilegítimo del gran Duque de Alba, apareciendo con el título de «La Variedad del Mundo». El prior don Fernando perteneció a la Orden de Malta de la que San Juan Bautista era el patrón, y no olvidemos también que, en la familia del Bosco. había un Jan van Aeken.

Desde antiguo son innumerables los textos que aluden al placer o deleite sexual en relación con Eva, y como causa de la perdición humana. Ya en Demócrito encontramos el siguiente pensamiento: «Salvación de la vida es despreocuparse de las cosas sexuales». Solón el ateniense nos dice: «Huye de aquellos placeres que paren en tristeza» y Periandro de Corinto «Los placeres son cosa mortal; las virtudes por el contrario son inmortales» ${ }^{13}$. Los pensamientos clásicos semejantes a los bíblicos sobre lo «perecedero de los placeres» pervivieron y abundaron en los Cancioneros medievales desde 1360 a $1520{ }^{14}$ y por poner un ejemplo castellano de ellos, acudimos a Don Iñigo de Mendoza en Vida de Nuestro redemtor ihesu Xpristo (1480): «Arderá tanto tu gana / que por la natura humana / querras pagar la mançana / con muerte de malhechor». Y en el Decir que fizo Juan Rodriguez del padron contra el Amor del Mundo: «Adán nuestro padre fue mal apreso / segund la Biblia claro se prueba / pues quiso quitar por amor de Eva / del fruto del árbol que le era defeso».

No nos debe de extrañar pues, que Fernando de Rojas acudiera para describir los símbolos del amor engañoso al texto de Eva y del Bautista. Pero, además, cuando leemos el Acto I

12 Agradezco a mi buen amigo y compañero Andrés Barcala, Investigador Científico del Departamento de Historia de la Iglesia del C.S.I.C., la ayuda prestada en la traducción del texto latino original.

El sentido clásico del verbo «ejicere» es abortar, y curiosamente en el Jardín de las Delicias no hay niños. Sobre el Bautista hay muchas referencias en los Cancioneros y de él se han ocupado los Padres de la Iglesia y San Bernardo coincidiendo en considerarle «trompeta del cielo», concepto muy relacionado con el Juicio Final.

13 Refranero, Poemas y Sentenciario de los filósofos griegos. Trad. original del griego al castellano por Juan David García Bacca. Caracas-Madrid, 1969.

${ }_{14}$ Cancionero del siglo XV ca 1360-1520. Ed. de Brian Dutton, vol. I. Salamanca, Universidad, 1990. 
inconscientemente se nos viene a la memoria la tabla central del tríptico del Jardín de las Delicias «el que verdaderamente ama es necesario que se turbe con la dulzura del soberano deleite... Y no sólo en la humana especie, mas en los peces, en las bestias, en las aves, en los reptiles y en lo vegetativo de algunas plantas han a este respecto ser machos y hembras»; Calixto, en el Acto IV, después de haber conseguido a Melibea, alude a la caducidad del placer: « OOh breve deleite mundano ¡ ¡Como duran poco y cuestan mucho tus dulzores!» ${ }^{15}$. Todavía, al final de la obra, cuando Pleberio llora el final de su hija Melibea, encontramos en sus palabras relaciones con el Jardín del Bosco «agora, visto el pro y la contra de tus bien andanças, me pareces un laberinto de errores ... juego de hombres que andan en corro, laguna llena de cieno, región llena de espinas, monte alto ... huerto florido y sin fruto, fuente de cuydados, no de lágrimas, mas de miseria ... dulce ponçoña, vana esperança, falsa alegría ... Cévasnos, mundo falso, con el manjar de tus deleytes; al mejor sabor nos descubres el anzuelo; no lo podemos huyr, que nos tiene ya caçadas las voluntades... Corremos por los prados de tus viciosos vicios (deleitosos vicios), muy descuydados, a rienda suelta,; descúbresnos la celada quando ya no hay lugar de volver» ${ }^{16}$.

ISABEL MATEO GómeZ Departamento de Arte C.S.I.C.

\section{OBRAS PARA DEFINIR LA PERSONALIDAD ARTÍSTICA DEL PINTOR DANIEL MARTÍNEZ, PADRE DE JUSEPE MARTÍNEZ}

La Biblioteca Nacional de Madrid conserva un dibujo de la Sagrada Familia (fig. 6), boceto preparatorio para una pintura del mismo tema que se encuentra en el Museo de Tapices de la Seo de Zaragoza (fig. 7) y ésta, a su vez, la debió mandar copiar el canónigo Mandura en 1602 en otra tabla, donde incluye su propio retrato, cuadro que donó a la iglesia de San Salvador de Ejea de los Caballeros (fig. 8).

El dibujo, realizado a lápiz y tinta marrón sobre papel beige $(200 \times 158 \mathrm{~mm}$.), está cuadriculado para su posterior ampliación, procede de la colección de Valentín Carderera

15 Los estudios de La Celestina han constatado la presencia del texto entre los clérigos y la extracción moral que hacían de él. Respecto al párrafo de los «deleites» en plantas, animales, etc., Russell (loc. cit. nota 8) dice que pudo ser inspirado por los textos del Tostado, quien a su vez los tomó de libros clásicos y bíblicos, que eran lugares comunes en la literatura europea de la época.

16 Russell considera que este párrafo está inspirado en Petrarca, De rebus familiar, publicada en 1496. En este texto existen muchas metáforas por las cuales se denuncia la vida en general, es ejemplo de lo que los retóricos llamaban «conglobatio» o aglomeración (loc. cit. nota 8, pp. 599-600, notas 31 a 33). Este presupuesto retórico nos trae a la memoria la denominación que, en fecha temprana, tuvo el tríptico: De la Variedad del Mundo, y en su forma de expresarlo. Yarza (loc. cit. nota 3, p. 66) cita un texto del siglo XVI de H. Mande muy similar al de La Celestina, pero el de Rojas es anterior. No cabe duda de que tanto Mande como Rojas, y el comitente del Bosco, utilizaron el texto de Petrarca. Todo ello habla en favor de que los textos literarios y las ideas circulaban y eran comunes a toda Europa en ciertos ambientes cultos y humanistas, tanto laicos como religiosos. El texto del Crisólogo y el contexto de la Crónica General de Schedel, están siendo revisados por mi para la próxima publicación, en este año 1999, de un libro sobre El Jardín de las Delicias. 